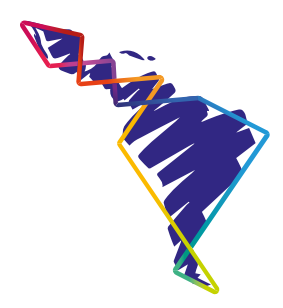

\title{
Protección Social en el marco de los Derechos Humanos
}

\author{
Social Protection within the \\ framework of Human Rights
}

\section{Proteção Social no âmbito dos Direitos Humanos}

\author{
Pedro César Cantú-Martínez
}

\begin{abstract}
Resumen
La protección social se ha constituido en un instrumento de carácter muy relevante desde el cual toda sociedad entrelaza actividades para edificar colectivos sociales con un mayor bienestar, donde toda persona accede a un trato justo e inclusivo, en un contexto de libertad y de progreso social permanente. Por este motivo, la protección social se ha considerado como un proceso que fortalece la aplicación de los derechos humanos. En el presente documento se hace un análisis de la protección social y su relación con los avances en esta materia en México, en el contexto de los derechos humanos.
\end{abstract}

Palabras clave: Protección social, derechos humanos, derechos fundamentales, desarrollo económico.

\begin{abstract}
Social protection has become a very relevant instrument from which every society intertwines activities to build social groups with greater well-being, where every individual has access to fair and inclusive treatment, within a context of freedom and permanent social progress. Thus, social protection has been considered as a process that strengthens the application of human rights. This document makes an analysis of social protection and its relationship with progress in this area in Mexico, in the context of human rights.
\end{abstract}

Recibido: 10-9-2019 - Aceptado: 13-5-2021

1 Académico e investigador de la Universidad Autónoma de Nuevo León adscrito a la Facultad de Ciencias Biológicas Unidad "A" en el Cuerpo Académico 181 de Ciencias Exactas y Desarrollo Humano. Correo electrónico: cantup@hotmail.com, pedro.cantum@uanl.mx (D) https://orcid.org/0000-0001-8924-5343 
Keywords: Social protection; Human rights; Fundamental rights; Economic development.

\section{Resumo}

A proteção social tornou-se um instrumento muito relevante a partir do qual toda sociedade entrelaça atividades para construir grupos sociais com maior bem-estar, onde todos tenham acesso a um tratamento justo e inclusivo, em um contexto de liberdade e progresso social permanente. Por isso, a proteção social tem sido considerada um processo que fortalece a aplicação dos direitos humanos. Este documento faz uma análise da proteção social e sua relação com o progresso nesta área no México, no contexto dos direitos humanos.

Palavras-chave: Proteção social; Direitos humanos; Direitos fundamentais; Desenvolvimento econômico.

\section{Introducción}

La protección social durante los últimos años se ha constituido en un soporte sumamente importante para toda sociedad, ya que en esta acción se conjugan distintas actividades encaminadas a la edificación de sociedades más racionales y comprensivas para abonar a niveles de vida más equitativos entre todas las personas (Cecchini y Robles, 2013). Su relevancia radica, sustancialmente, en considerar y velar sobre cómo resarcir las privaciones distintivas de grupos de población contemplados como vulnerables. El término vulnerabilidad se emplea para aquellos individuos o conjuntos de población que, por sus circunstancias -edad, género, situación civil, origen étnico o condición social- se hallan en un contexto de inseguridad que les imposibilita integrarse plenamente al desarrollo económico y así acceder a mejores escenarios de prosperidad y bienestar. Es decir, donde como seres humanos puedan expresar todas sus capacidades y desplegar expresiones como la creatividad en un marco de libertad (Boltvinik, 2005).

Amrtya Sen (1998), filósofo y economista hindú, determina el concepto de capacidades como las prerrogativas que tiene un individuo para desarrollar distintas actividades, y que le posicionan con ciertas ventajas sobre otros que no las ostentan, como son la alimentación, la salud, la educación, entre otros factores. Por lo tanto, las capacidades mencionadas por Sen permiten evaluar, en primera instancia, el bienestar individual de una persona y, por otra parte, entretejer esta condición a un ámbito grupal y social (Urquijo, 2014). Con esto, le permite exponer, principalmente, las eventualidades que aquejan al bienestar humano, las cuales se articulan en los distintos escenarios de la realidad mundial como miseria, desigualdad, injusticia social y, por lo tanto, una inexistencia de desarrollo humano. Por estos motivos, la protección social, como intervención de carácter social realizada por el Estado, se ha erguido como el instrumento en el que recae primordialmente 
parte de la responsabilidad para garantizar un incuestionable nivel de bienestar socioeconómico que debe prevalecer para todo miembro de una colectividad social (Cecchini y Martínez, 2011).

En este sentido, Cecchini y Martínez (2011, p. 19) señalan las actividades que atiende la protección social.

Se ocupan tanto de las necesidades de protección y promoción de quienes se encuentran en situación de pobreza y pobreza extrema, como de las de aseguramiento de quienes, no siendo pobres, deben sentirse seguros ante circunstancias adversas y determinadas etapas del ciclo de vida.

De esta manera, en el marco de los derechos humanos, la protección social se ha constituido en un bastión relevante para buscar aminorar los estragos de la miseria, la desigualdad social y promover, con ello, escenarios de mayor inclusión social, donde subsista mayor protección para las personas sin distinción alguna.

Es así cómo, en el presente manuscrito, se lleva a cabo una reflexión que tiene como derrotero conducirse por la línea de determinar los orígenes y fuentes de la protección social, observar los progresos en esta materia y adentrarse en los principios de carácter reglamentario que se ostentan en en México. Todo ello en el marco de los derechos humanos, para posteriormente realizar unas consideraciones finales al respecto.

\section{Derechos humanos}

\section{Historia de los derechos humanos}

Horacio Spector (2015) señala que coexistimos en una época de múltiples y grandes contrariedades morales, entre las que descuella lo relacionado con los derechos humanos. Esta conciencia de carácter ecuménica surge primordialmente cuando el 26 de junio de 1945 se suscribe la nombrada Carta de las Naciones Unidas, que particularmente en el Capítulo X alusivo al Consejo Económico y Social y en su Artículo 68 menciona: "El Consejo Económico y Social establecerá comisiones de orden económico y social y para la promoción de los derechos humanos, así como las demás comisiones necesarias para el desempeño de sus funciones" (Naciones Unidas, 1945). Y a partir de su entrada en vigor $\quad-24$ de octubre de 1945- se resuelve actuar de acuerdo con lo declarado en el preámbulo de dicho documento, que señala el compromiso: 
- a preservar a las generaciones venideras del flagelo de la guerra que dos veces durante nuestra vida ha infligido a la Humanidad sufrimientos indecibles,

- $\quad$ a reafirmar la fe en los derechos fundamentales del hombre, en la dignidad y el valor de la persona humana, en la igualdad de derechos de hombres y mujeres y de las naciones grandes y pequeñas,

- a crear condiciones bajo las cuales puedan mantenerse la justicia y el respeto a las obligaciones emanadas de los tratados y de otras fuentes del derecho internacional,

- $\quad$ a promover el progreso social y a elevar el nivel de vida dentro de un concepto más amplio de la libertad.

Fue así que en el marco de la Consejo Económico y Social surge la génesis de la Comisión de Derechos Humanos que, tras tres años posteriores a su creación, en el documento resolutivo proveniente de la Asamblea General el 10 de diciembre de 1948 se proclama la Declaración Universal de Derechos Humanos (Naciones Unidas, 1948). En cuyo Artículo 1 centra el fundamento de su promulgación, al indicar que: "Todos los seres humanos nacen libres e iguales en dignidad y derechos $\mathrm{y}$, dotados como están de razón y conciencia, deben comportarse fraternalmente los unos con los otros". Primordialmente esta declaración prorrumpe por la segunda conflagración bélica mundial, que arrojó una inconmensurable movilización de recursos materiales como humanos y que conllevó un sinnúmero de víctimas mortales como también de personas desplazadas de sus lugares de origen (Ayén, 2010). Así, tras las crueldades perpetradas durante la Segunda Guerra Mundial se originó una sucesión de avances en el contexto internacional en el ámbito de los derechos humanos (ver Tabla1), donde todas estas iniciativas contemplan herramientas de vigilancia de la observancia de sus disposiciones.

Posteriormente, en 2006, se crea el Consejo de los Derechos Humanos en el marco de la Asamblea General de las Naciones Unidas, que viene a suceder a la Comisión de Derechos Humanos, con lo cual se busca, mediante este nuevo cuerpo colegiado, obtener mayor legitimidad en el ámbito internacional en materia de protección de los derechos humanos (Centro por la Justicia y el Derecho Internacional, 2007). 


\section{Tabla 1}

\section{Convenciones, pactos y declaraciones en materia de derechos humanos}

\section{Reuniones en siglo XX}

Convención sobre Prevención y Sanción del

Delito de Genocidio (1948)

Declaración de Helsinki relativa a los trabajos

de investigación biomédica con sujetos

humanos (1964)

Pacto Internacional de Derechos Económicos

Sociales y Culturales (1966)

Pacto Internacional de Derechos Civiles y

Políticos (1966)

Convención Internacional sobre la Eliminación

de todas las Formas de Discriminación Racial

(1967)

Declaración sobre la Raza y los Prejuicios

Raciales (1978)

Convención sobre la Eliminación de todas las

Formas de Discriminación contra la Mujer

(1979)

Guías éticas internacionales para investigación biomédica que involucra a seres humanos del

Consejo de Organizaciones Internacionales de

Ciencias Médicas (1982)

Convención contra la Tortura y otros Tratos

o Penas Crueles, Inhumanos o Degradantes

(1984)

Convención sobre los Derechos del Niño (1989)

Convenio sobre pueblos indígenas y tribales en países independientes (1989)

Normas uniformes de las Naciones Unidas

sobre la igualdad de oportunidades para las

personas con discapacidad (1993)

Declaración Universal sobre el Genoma

Humano y los Derechos Humanos (1997)

Declaración sobre las Responsabilidades

de las Generaciones Actuales para con las

Generaciones Futuras (1997)

Estatuto de Roma para la Corte Penal

Internacional (1998)

\section{Reuniones en siglo XXI}

Declaración Universal sobre la

Diversidad Cultural (2001)

Declaración Internacional sobre los

Datos Genéticos Humanos (2003)

Declaración Universal sobre Bioética y Derechos Humanos (2005)

Convención Internacional para la

Protección de todas las Personas contra las Desapariciones Forzadas (2006)

Nota: Elaboración propia. 


\section{Naturaleza y oportunidades de los derechos humanos}

Túnnermann (1997), en su obra sobre los derechos humanos, indica que el derrotero de nuestra sociedad se ha distinguido por una serie de antecedentes donde tanto mujeres como varones han combatido, algunas veces de forma aciaga, por alcanzar el disfrute pleno de los derechos que les corresponden por pertenecer a una sociedad, a esas prerrogativas se les denomina, en la actualidad, derechos humanos. Por esta razón el maestro Carlos García Bauer (citado por Túnnermann, 1997, p. 26) menciona que tras la Declaración Universal de los Derechos Humanos:

Por primera vez se consagró, en un documento de validez universal, en forma precisa, el mínimo de derechos que el hombre debe gozar sobe la tierra, sea cual fuere el lugar en que se encuentre. Del 10 de diciembre de 1948 en adelante, los pueblos del mundo saben cuáles son sus derechos fundamentales y habrán de exigir cada vez más su estricto cumplimiento.

Entre las características cardinales que ostentan, encontramos que los derechos humanos, de acuerdo con la Comisión Nacional de los Derechos Humanos (2016) en México, indican que estos son universales, ya que corresponden a todos los seres humanos de manera inmanente, y además son indivisibles e interdependientes de tal manera que no existe un derecho mayor que otro y, además, son ineluctables.

Sin embargo, los derechos humanos solo fructificaran en una sociedad organizada civilmente mediante mecanismos democráticos, ya que, como alude García (2018), es en una sociedad democrática donde los derechos humanos progresan o bien menguan conjuntamente. Tal como lo señala el Artículo 2 de la Declaración Universal de los Derechos Humanos (Naciones Unidas, 1948):

Toda persona tiene los derechos y libertades proclamados en esta Declaración, sin distinción alguna de raza, color, sexo, idioma, religión, opinión política o de cualquier otra índole, origen nacional o social, posición económica, nacimiento o cualquier otra condición. Además, no se hará distinción alguna fundada en la condición política, jurídica o internacional del país o territorio de cuya jurisdicción dependa una persona, tanto si se trata de un país independiente, como de un territorio bajo administración fiduciaria, no autónomo o sometido a cualquier otra limitación de soberanía.

En este sentido, Spector (2015) también hace alusión a que el asentimiento a esta proclama en el concierto internacional se sustentó en que a los derechos solo fue necesario sustituirles la palabra naturales por la de humanos para que su aceptación 
fuera de manera universal. Esos derechos humanos que pueden contemplar particularidades tan primordiales - para un persona- como la alimentación hasta las más complicadas que conllevan el respeto, la participación en la vida comunitaria y el poder expresarse en público sin temor a ser reprendida. Es decir, todo ser humano tiene derecho a la vida, expresada en términos de su libertad y seguridad, la cual debe alcanzar en su propia persona al pertenecer a una sociedad. Por tanto, los derechos humanos procuran la mejora del escenario de aplicación de las políticas públicas, estimulando una orientación de orden intersectorial e interdisciplinario para garantizar los derechos humanos que le son inmanentes a toda persona.

De esta manera, considerando que en la actualidad subsiste un floreciente número de pactos, tratados y declaraciones sobre derechos humanos, es oportuno hacer hincapié en que estos mismos requieren una insistente lectura para su reajuste y definición (García, 2018), con la finalidad de que dichas disposiciones convenidas puedan prevalecer en el marco de la conciencia social y de las aplicaciones jurídicas, ya que muchas de estas están alineadas a los derechos sociales que frecuentan incluir aspectos relacionados con aquellas condiciones que se requieren para vivir dignamente como alimentación, educación, salud trabajo y prestaciones sociales entre otras (Sastre, 2001). Por lo tanto, esto exige lo siguiente:

La adopción de decisiones políticas que están condicionadas por las circunstancias económicas, pero éstas no deben ser concebidas como una excusa insalvable para limitar su capacidad de realización práctica, sobre todo si se trata de derechos que plantean un cambio en las relaciones económicas para posibilitar el ejercicio en serio de los derechos, que es una manera de completar la tarea iniciada con su reconocimiento. (Sastre, 2001, p. 270)

En este aspecto, los derechos humanos requieren estar insertos en los marcos jurídicos vigentes para el cumplimiento de sus postulados. Esto se sostiene en la argumentación de que el ser humano es un ente que ostenta dignidad y, por lo tanto, destinatario de la titularidad de estas atribuciones (González, 1998).

\section{Derechos humanos en México}

De acuerdo con las tendencias actuales en el concierto internacional, se puede identificar que "con los tratados en materia de derechos humanos las obligaciones van dirigidas a medidas para la protección de los derechos de las personas [en todas las naciones] ..., integrando al orden interno una nueva fuente de protección de estos derechos" (Castañeda, 2018, p. 11). Por lo cual, en México, durante el año 1989, se crea, dentro de la estructura administrativa de la Secretaría de Gobernación, la Dirección General de Derechos Humanos, para posteriormente en 
el año 1990, erigir, por decreto presidencial, la Comisión Nacional de Derechos Humanos (Secretaría de Gobernación, 1990). En dicha disposición, en el Artículo 3 , se señalan las funciones sustantivas de la Comisión en México:

I. Proponer la política nacional en materia de respeto y defensa a los derechos humanos;

II. Establecer los mecanismos de coordinación que aseguren la adecuada ejecución de la política nacional de respeto y defensa a los derechos humanos;

III. Elaborar y ejecutar los programas de atención y seguimiento a los reclamos sociales sobre derechos humanos;

IV. Elaborary proponer programas preventivos en materia de derechos humanos, en los ámbitos jurídico, educativo y cultural para la Administración Pública Federal;

V. Representar al Gobierno Federal ante los organismos nacionales y en coordinación con la Secretaría de Relaciones Exteriores, ante los internacionales, en cuestiones relacionadas con la promoción y defensa de los derechos humanos;

VI. Formular programas y proponer acciones que impulsen el cumplimiento dentro del territorio nacional de los tratados, convenios y acuerdos internacionales asignados por nuestro país.

Más adelante, en 1992, por iniciativa del Ejecutivo Nacional, se reforma el Artículo 102 de la Constitución Política de México, adicionando un Apartado B, que indica:

El Congreso de la Unión y las legislaturas de los Estados en el ámbito de sus respectivas competencias, establecerán organismos de protección de los Derechos Humanos que otorga el orden jurídico mexicano, los que conocerán de quejas en contra de actos u omisiones de naturaleza administrativa provenientes de cualquier autoridad o servidor público, con excepción de los del Poder Judicial de la Federación, que violen estos derechos. Formularán recomendaciones públicas autónomas, no vinculatorias y denuncias y quejas ante las autoridades respectivas. (Secretaría de Gobernación, 1992)

De esta forma, la Comisión Nacional de Derechos Humanos en México fue elevada a un rango constitucional y en un régimen jurídico de organismo descentralizado, para subsiguientemente. en 1999, lograr su autonomía presupuestaria (Comisión Nacional de los Derechos Humanos, 2016). Finalmente, años después, en 2011, se suscribe el decreto por el que se reforman 11 artículos de la Constitución Política de México, que fueron el 1, 3, 11, 15, 18, 29, 33, 89, 97, 102 y 105, con lo cual se elevan a rango constitucional los derechos humanos en México (Suprema Corte 
de Justicia de la Nación, 2011). Al respecto, Cienfuegos (2017) destaca que en la Constitución Política de México las modificaciones principales conllevaron cambios en sus alcances y pasan de garantías individuales a los derechos humanos y sus garantías. Y, adicionalmente, esto queda cristalizado en el Artículo 102 que, en su contenido sentencia que la Comisión de Nacional de Derechos Humanos queda facultada para investigar las violaciones a estos o cuando la autoridad correspondiente lo solicite.

\section{Protección social}

\section{Orígenes y fuentes de la protección social}

Cabrera (2011) menciona que los antecedentes de la protección social son bastante recientes y de acuerdo con el marco del derecho internacional existente, la protección social -denominada también como seguridad social-prospera en el concierto mundial cuando se hace mención en el Artículo 22 de la Declaración Universal de los Derechos Humanos, en 1948, de lo siguiente:

Toda persona, como miembro de la sociedad, tiene derecho a la seguridad social, y a obtener, mediante el esfuerzo nacional y la cooperación internacional, habida cuenta de la organización y los recursos de cada Estado, la satisfacción de los derechos económicos, sociales y culturales, indispensables a su dignidad y al libre desarrollo de su personalidad. (Naciones Unidas, 1948)

Y más adelante, en este mismo pronunciamiento, en el Artículo 25, detalla cuáles condiciones elementales le son necesarias a todo ser humano:

Toda persona tiene derecho a un nivel de vida adecuado que le asegure, así como a su familia, la salud y el bienestar, y en especial la alimentación, el vestido, la vivienda, la asistencia médica y los servicios sociales necesarios; tiene asimismo derecho a los seguros en casos de desempleo, enfermedad, invalidez, viudez, vejez u otros casos de pérdida de sus medios de subsistencia por circunstancias independientes a su voluntad, (Naciones Unidas, 1948)

Por lo tanto, la protección social es la derivación de una dilatada lucha social que se inicia en el siglo XVII y XVIII en el marco de la revolución industrial, y que se expande mundialmente desde mediados del siglo pasado con la pronunciación de los derechos humanos y que se continúa hasta el presente en nuestra sociedad (Cabrera, 2011). Paúl Durand (citado por Nugent, 1997, p. 606), menciona que la protección social ha transitado por tres etapas, la primera que se denomina: "Procedimientos Indiferenciados de Garantía, que son: el ahorro individual, la 
mutualidad, el seguro privado, la asistencia pública y la responsabilidad; la segunda es la de los Seguros Sociales, y la tercera, la de la Seguridad Social”.

En esta misma línea discursiva, García (2014) hace mención a que, en el año de 1952, se erigió el Convenio 102 -por parte de la Organización Internacional del Trabajo- el cual se nombró como Norma Mínima de Seguridad Social en la cual detalla que la seguridad social enmarca medidas en procura de proteger a las personas de las secuelas derivadas de los abundantes riesgos sociales enfrentados, tales como las enfermedades, los accidentes de trabajo, la invalidez, la vejez, entre otros aspectos.

Con lo anterior, se le otorga a la estructura gubernamental una gran responsabilidad para regular la política social, es decir, para abonar un equilibrado desarrollo socioeconómico mediante la implementación de marcos regulatorios, programas y otorgamiento de servicios de seguridad social.

Es pertinente mencionar que la seguridad social se constituye en un coadyuvante para alcanzar y concretar los tan anhelados derechos económicos, sociales y culturales que le son inmanentes a todo ser humano (Comisión Nacional de los Derechos Humanos, 2012). Esto queda explícito en el Artículo 10 de estos mismos pronunciamientos, que cita toda persona:

Derecho a la más amplia protección y asistencia a la familia. Contempla el derecho a contraer matrimonio libremente; la obligación de prestar protección a las madres antes y después del parto, otorgarles licencia remunerada y otras prestaciones, si trabajan, así como adoptar medidas para asistir y proteger a niños y adolescentes de la explotación económica y social.

Lo anterior involucra, en esta declaratoria del derecho al trabajo (Artículo 6), derecho a la seguridad social y al seguro social (Artículo 9), derecho a un apropiado nivel de vida (Artículo 11), derecho contar con una mejor salud (Artículo 12), derecho a la educación (Artículo 13), derecho a la educación primaria universal gratuita (Artículo 14) y derecho a participar en la vida cultural y gozar de los progresos científicos (Artículo 15). Es así que, en términos generales, la protección social busca mejorar las condiciones de bienestar y garantizar la seguridad de toda persona, y también hacer frente a los rezagos de orden socioeconómico en el mundo; posee, además, una honda repercusión en todas las situaciones y segmentos de la sociedad, y favorece la cohesión social y el desarrollo de todo colectivo social.

Lo anterior lo sentencia con suma exactitud Díaz (2000), al indicar que, en el mismo progreso de las comunidades humanas, siempre ha estado presente el encontrar 
los medios más equitativos y las prácticas necesarias para proveerse un bienestar social tanto presente como futuro. Esto es, se yergue constantemente la exigencia de revisión de los esquemas de protección social, con la finalidad de beneficiar a toda persona, en el marco de un derecho positivo.

\section{Progreso de la protección social en México}

La conjunción de la protección social en México, de manera universal, de acuerdo con Díaz (2000), se establece en el marco de dividir la población en trabajadores en general, en servidores públicos y la población en general carente de una relación laboral. El origen de la seguridad social de los trabajadores en México surge de una iniciativa impulsada en 1935 por el presidente Lázaro Cárdenas, y gestada por el licenciado Ignacio García Téllez, que describía la concretización de una instancia institucional -Instituto Mexicano del Seguro Social (IMSS)- una de cuyas características principales es que contaría con aportaciones económicas de los asegurados, patrones y Estado (IMSS, 2017). Sin embargo, no fue sino hasta 1943 cuando se fundó, bajo la tutela presidencial de Manuel Ávila Camacho. Entre las finalidades que contemplaba su creación está la de garantizar el bienestar de las personas, la atención en salud y, además, asegurar los medios de subsistencia para cumplir con el precepto del derecho humano a la salud (IMSS, 2017). Desde su creación, el IMSS se constituyó como un organismo descentralizado, autónomo $\mathrm{y}$ con patrimonio propio.

Mientras la seguridad social de los trabajadores al servicio del Estado estuvo encomendada al Instituto de Seguridad y Servicios Sociales de los Trabajadores del Estado (ISSSTE), el cual tiene su sustento en el año de 1960 en el régimen presidencial de Adolfo López Mateos. El Artículo 123 de la constitución mexicana fue reformado (Díaz, 2000) y esto conllevo que la seguridad social que otorgar esta nueva instancia institucional, se organizará así:

Catorce prestaciones de carácter obligatorio: dos seguros para proporcionar servicios de salud (seguro de enfermedades no profesionales y maternidad y seguro de accidentes de trabajo y enfermedades profesionales); cinco seguros de carácter pensionario (jubilación, vejez, invalidez, fallecimiento e indemnización global); tres prestaciones relacionadas con vivienda (créditos para la adquisición y construcción de vivienda, préstamos hipotecarios y arrendamiento de habitaciones económicas), préstamos a corto plazo y tres servicios sociales (servicios para la readaptación y reeducación de inválidos, promociones para elevar la preparación técnica y cultural del trabajador y su familia). (Centro de Estudios de las Finanzas Públicas, 2009) 
Finalmente, la protección social de la población no sujeta a una relación de trabajo principia con la creación de la Secretaría de Salubridad y Asistencia, el 15 octubre de 1943, para ser atendida de forma asistencial por el Estado. A quienes se les nombra como población abierta, son, principalmente, personas de escasos recursos (Secretaría de Salud, 2005). Posteriormente en 2005, bajo la instancia presidencial de Vicente Fox, se erige un planteamiento de protección social, en cuyo sistema contempló un fondo de ahorro para jubilaciones y pensiones, un programa de vivienda y un régimen para la salud designado como Seguro Popular. La población atendida en este nuevo esquema incluye, entre otros, a grupos de personas autoempleadas, trabajadores que realizan actividades de forma independiente y población vulnerable, indígena y campesina, carentes de cobertura por las otras dos instancias, IMSS e ISSSTE. Esta acción se ha encaminado a reducir las diferencias existentes entre la población en México, creando oportunidades similares para abatir las inequidades en materia de protección social, sustentado esto principalmente en un trato justo y no en el marco de la influencia social (Flamand y Moreno-Jaimes, 2014).

\section{Contexto social en México}

Para comprender el contexto social en México es preciso recurrir a fuentes oficiales y documentales, que nos permitan mostrar algunos indicadores para apreciar la trascendencia de la protección social y las condiciones de cumplimiento o no de los derechos humanos. México, de acuerdo con el Instituto Nacional de Estadística y Geografía (INEGI), está constituido por una población bastante numerosa que alcanza la cifra de 119,98 millones; el promedio de escolaridad de la población de 15 y más años es de 9,2 años y la población de 15 años y más sin instrucción superior es de $81,4 \%$. Además, México cuenta con una población de 5 años y más hablante de lengua indígena de 6,69 millones de personas (INEGI, 2018).

Esta misma institución -INEGI- indica que, en el ámbito del balance comercial, México cuenta con déficit de 193,9 millones de dólares entre las exportaciones y las importaciones que lleva a cabo. Por otra parte, también cita que cuenta en el segundo trimestre de 2018, con 56,64 millones de personas en la condición de población económicamente activa, de las cuales, el 56,65\% está en una condición de informalidad laboral, esto es, población ocupada, que trabaja desde el hogar-no como una empresa- de tal manera que las actividades emprendidas no son cuantificables. Por otra parte, $15,37 \%$ se encuentra en situación crítica laboral, que refiere a todas aquellas personas que están ocupadas, pero trabajan menos de 35 horas a la semana, o bien, a las que trabajan más de 35 horas y reciben una remuneración al mes menor al salario mínimo y, finalmente, se encuentran también incluidas 
aquellas personas que trabajan más de 48 horas a la semana y solo reciben una retribución como máximo de dos salarios mínimos.

En el rubro de salud y seguridad social, el INEGI (2018) reporta que el mayor porcentaje de derechohabientes se encuentra amparado por el Seguro Popular, cuya cifra es de 49,9\%, le siguen los derechohabientes del Instituto Mexicano del Seguro Social (IMSS) con 39,2 \%, continúa el Instituto de Seguridad y Servicios Sociales de los Trabajadores del Estado (ISSSTE) con 7,7 \%, Otras instituciones 4,8 \% y, finalmente, los derechohabientes de Petróleos Mexicanos, Secretaría de la Defensa Nacional o Secretaría de Marina con 1,2\%. Mientras, en el escenario de pobreza en México, de acuerdo con el Consejo Nacional de Evaluación de la Política de Desarrollo Social (CONEVAL), se encuentra el 43,6 \%, condición que equivale a 53,4 millones de personas y en pobreza extrema el 7,6 \% de la población, que corresponde a 9,4 millones de personas en el país (CONEVAL, 2018).

En el ámbito de la seguridad alimentaria, Shamah-Levy, Mundo-Rosas y Rivera-Dommarco (2014) indican:

En México 7 de cada 10 hogares presentan algún grado de inseguridad alimentaria (41.6\% IA leve, $17.7 \%$ IA moderada y $10.5 \%$ IA severa). El total de hogares con IA moderada y severa (28.3\%) representa alrededor de 8,322,486 hogares, que tuvieron que disminuir la cantidad de alimentos consumidos o experimentaron hambre.

Por otra parte, Aguirre, García, Vázquez y Alvarado y Romero (2017, p. 743), indican que para México se "estimó que 302279 (2,8\%) menores de cinco años de edad presentan bajo peso, 1467757 (13,6\%) baja talla y 171982 (1,6\%) emaciación o desnutrición severa, en todo el país".

Como se aprecia en esta breve descripción, en México aún subsisten relevantes rezagos que no se han resuelto y donde persisten aún punzantes discrepancias en materia de protección social; se advierte que existen dos mundos desiguales en un mismo plano nacional. En uno se han dejado millones de hogares disminuidos económicamente o bien que tienen que aceptar la carga emocional de ver a los miembros de sus familias padecer enfermedades y hambre (Secretaría de Salud, 2005), lo que finalmente produce exclusión social y carencia del cumplimiento de los derechos humanos, como también de protección social.

\section{Consideraciones finales}

Se está de acuerdo en que la protección social, en la actualidad en México, exige la vigencia de una serie de condiciones promovidas por el Estado, con la finalidad de dilatar la vida de las personas, hacer prevalecer la dignidad humana y fortalecer 
la unión social. En alusión a esto, se ha pronunciado que todas las personas cuentan con los mismos derechos, los cuales son comunes y le conciernen a cada ser humano. Frente a esta representación, la protección social se yergue como uno de los instrumentos para hacer transitar a todo colectivo social a un escenario donde se puedan desarrollar todas las capacidades humanas.

Sin embargo, para esto es pertinente seguir fortaleciendo las estructuras públicas y privadas, para que se encaminen al progreso del patrimonio social. Este se constituye de manera tangible en el agregado de derechos, bienes y obligaciones -que ostentan tanto personas físicas como morales- para garantizar el acceso equitativo y justo a los beneficios del desarrollo económico. Por consiguiente, ello podrá llevarse a cabo mediante la protección social que permitirá garantizar una mejor calidad de vida, una mejoría de carácter económico, mejores pensiones, elevar la preparación académica, tener acceso a la salud; pero, sobre todo, el respeto de los derechos humanos, aspectos que son vitales tanto individualmente como de forma colectiva.

En definitiva, la protección social como un derecho humano se constituye en el mecanismo social para corregir las desigualdades e inequidades, producto de las diferencias económicas existentes entre las personas, no importando así las peculiaridades sociales y laborales que estas ostenten.

\section{Referencias}

Aguirre, H., García, J. F., Vázquez M. C., Alvarado A. M. y Romero, H. (2017). Panorama general y programas de protección de seguridad alimentaria en México. Revista Médica Electrónica, 39(supl 1), S741-S749. http://scielo.sld.cu/scielo. php?script=sci_arttext\&pid=S1684-18242017000700005

Ayén, F. (2010). La Segunda Guerra Mundial. Causas, desarrollo y repercusiones (Sección Temario de oposiciones de Geografía e Historia), Proyecto Clío 36. http://clio.rediris. es/n36/oposicones/tema70.pdf

Boltvinik, J. (2005). Ampliar la mirada. Un nuevo enfoque de la pobreza y el florecimiento humano. Papeles de Población, 11(44), 9-42. http://www.scielo.org.mx/scielo. php?script=sci_arttext\&pid=S1405-74252005000200002

Cabrera, C. J. (2011). Política y seguridad social en México. En C. J. Cabrera Adame y A. A. Gutiérrez Lara (Coords.), La protección social en México (pp. 21-76). Universidad Nacional Autónoma de México. http://ru.economia.unam.mx/130/1/11. Cabrera\%2C\%20CJ.\%20Pol\%C3\%ADtica\%20y\%20seguridad\%20social $\% 20$ en $\% 20$ M\%C3\%A9xico.pdf

$82 \begin{aligned} & \text { Revista Latinoamericana de Derechos Humanos } \\ & \text { Volumen 32 (2), II Semestre 2021 } \\ & \text { ISSN: 1659-4304 • EISSN: 2215-4221 }\end{aligned}$ 
Castañeda, M. (2018). El principio pro persona ante la ponderación de derechos. Comisión Nacional de los Derechos Humanos. https://www.cndh.org.mx/documento/ el-principio-pro-persona-ante-la-ponderacion-de-derechos

Cecchini, S. y Martínez, R. (2011). Protección social inclusiva en América Latina. Una mirada integral, un enfoque de derechos. CEPAL-GIZ. https://www.cepal.org/es/ publicaciones/2593-proteccion-social-inclusiva-america-latina-mirada-integral-un-enfoque-derechos

Cecchini, S. y Robles, C. (2013). Prólogo. En E. Valencia Lomelí, D. Foust Rodríguez y D. Tetreault Weber. Sistemas de protección social en América Latina y el Caribe: México. (pp. 5-6). CEPAL-GIZ. https://repositorio.cepal.org/handle/11362/4035

Centro de Estudios de las Finanzas Públicas. (2009). El Instituto de Seguridad y Servicios Sociales de los Trabajadores del Estado (ISSSTE) a dos años de la reforma. CEFP. http://www.cefp.gob.mx/intr/edocumentos/pdf/cefp/2009/cefp0482009.pdf

Centro por la Justicia y el Derecho Internacional. (2007). La protección de los derechos humanos en el Sistema Interamericano. Guía para defensores/as de DDHH. CEJIL y Fundación Sueca para Derechos Humanos. https://www.cejil.org/sites/default/files/ legacy_files/GuiaDH2012Links.pdf

Cienfuegos, D. (2017). Una historia de los derechos humanos en México. Comisión Nacional de los Derechos Humanos. http://appweb.cndh.org.mx/biblioteca/archivos/pdfs/ Historia-DH-Mexico-Reconocimiento.pdf

Comisión Nacional de los Derechos Humanos (2012). Pacto internacional de derechos humanos económicos, sociales y culturales, y su protocolo facultativo. Comisión Nacional de los Derechos Humanos. https:/www.cndh.org.mx/sites/all/doc/carti1las/7_Cartilla_PIDESCyPF.pdf

Comisión Nacional de los Derechos Humanos. (2016). Contra el abuso del poder, la Comisión Nacional de los Derechos Humanos defiende y promueve tus derechos humanos. Comisión Nacional de los Derechos Humano.http://appweb.cndh.org.mx/biblioteca/ archivos/pdfs/cua-Comision-Nacional-Derechos-Humanos.pdf

CONEVAL (2018). Pobreza en México. https://www.coneval.org.mx/Medicion/Paginas/ PobrezaInicio.aspx

Díaz, J. (2000). La seguridad social en México. Un enfoque histórico (Primera parte). Revista Jurídica de la Escuela Libre de Derecho de Puebla, 2, 39-59. https://revistas-colaboracion.juridicas.unam.mx/index.php/juridica-libre-puebla/article/view/569/519 
Flamand,L.,\&Moreno-Jaimes, C.(2014). Seguropopulary federalismoen México.Unanálisis de política pública. Centro de Investigación y Docencia Económicas. http://www.libreriacide. $\mathrm{com} / ? \mathrm{P}=$ producto $\&$ PRODfamily=libros $\&$ PRODclassification $=1 \&$ PRODproduct $=2427$

García, M. (2014). Derecho a la seguridad social. Estudios Políticos, 9(32), 83-113. https:// doi.org/10.1016/S0185-1616(14)70582-7

García, S. (2018). Panorama de la jurisprudencia interamericana sobre derechos humanos. Comisión Nacional de los Derechos Humanos. https://www.cndh.org.mx/documento/ panorama-de-la-jurisprudencia-interamericana-sobre-derechos-humanos

González, A. M. (1998). Derecho natural y derechos humanos: Síntesis práctica y complementariedad teórica. Tópicos, 15, 73-98. https://doi.org/10.21555/top.v15i1.399

IMSS. (2017). Los Rostros del IMSS. Instituto Mexicano del Seguro Social. http://www. imss.gob.mx/sites/all/statics/75aniv/IMSS75-book.pdf

INEGI. (2018). México en cifras. https:/www.inegi.org.mx/app/areasgeograficas/

Naciones Unidas. (1945). Carta de las Naciones Unidas. http://www.un.org/es/ charter-united-nations/

Naciones Unidas. (1948). La Declaración Universal de Derechos Humanos. http://www. un.org/es/universal-declaration-human-rights/

Nugent, R. (1997). La seguridad social: Su historia y sus fuentes. En N. de Buen Lozano y E. Morgado Valenzuela (Coords.), Instituciones de derecho del trabajo y de la seguridad social (pp. 603-622). Universidad Nacional Autónoma de México. https:// archivos.juridicas.unam.mx/www/bjv/libros/1/139/1.pdf

Sastre, S. (2001, abril-junio). Hacia una teoría exigente de los derechos sociales. Revista de Estudios Políticos, 112, 253-270. https://recyt.fecyt.es/index.php/RevEsPol/article/ download/46584/28068

Secretaría de Gobernación. (1990). Decreto por el que se crea la Comisión Nacional de Derechos Humanos como un órgano desconcentrado de la Secretaría de Gobernación. DOF: 06/06/1990. http://www.dof.gob.mx/nota_detalle. php? codigo $=4659530 \&$ fecha $=06 / 06 / 1990$

Secretaría de Gobernación. (1992). Decreto por el que se reforma el Artículo 102 de la Constitución Política de los Estados Unidos Mexicanos. DOF: 28/01/1992. http://www. dof.gob.mx/nota_detalle.php?codigo=4646760\&fecha=28/01/1992 
Secretaría de Salud. (2005). Sistema de Protección Social en Salud. Elementos conceptuales, financieros y operativos. Secretaría de Salud-Unidad de Análisis Económico. http:// www.salud.gob.mx/unidades/cdi/documentos/DOCSAL7723.pdf

Sen, A. (1998). Capacidad y bienestar. En M. C. Nussbaum y A. Sen (Comp.), La calidad de vida (pp. 54-83). Fondo de Cultura Económica. https://elfondoenlinea.com/Detalle. aspx?ctit=001655R

Shamah-Levy, T. Mundo-Rosas, V. y Rivera-Dommarco, J. A. (2014). La magnitud de la inseguridad alimentaria en México: Su relación con el estado de nutrición y con factores socioeconómicos. Salud Pública de México, 56(supl 1), S79-S85. https://doi. org/10.21149/spm.v56s1.5169

Spector, H. (2015). Derechos humanos. En J.L. Fabra Zamora y V. Rodríguez Blanco (Eds.), Enciclopedia de filosofia y teoría del derecho (pp. 1521-1569). Universidad Nacional Autónoma de México. https://dialnet.unirioja.es/servlet/libro?codigo=708849

Suprema Corte de Justicia de la Nación. (2011). Decreto por el que se modifica la denominación del Capítulo I del Título Primero y reforma diversos artículos de la Constitución Política de los Estados Unidos Mexicanos. http://www2.scjn.gob.mx/red/ constitucion/10Junio.html

Túnnermann, C. (1997). Los derechos humanos: Evolución histórica y reto educativo. UNESCO. https://www.enriquebolanos.org/media/publicacion/3150.pdf

Urquijo Angarita, M. J. (2014, diciembre). La teoría de las capacidades en Amartya Sen. EDETANIA 46, 63-80. https://dialnet.unirioja.es/descarga/articulo/5010857.pdf 
